\title{
Using a personal response system for promoting student interaction
}

Ray d'Inverno, Hugh Davis and Su White

Accepted August 2003

\begin{abstract}
We first descibe the introduction of an electronic feedback system in a large lecture class in Engineering Mathematics designed to promote greater student interaction. We then look at the experience of using the system where it was primarily used to support the consolidation of key concepts in tutorials in Computer Science. We discuss the issue of how the introduction of such methods turned out to be as much a learning experience for the academics involved as for the students and consider the potential of these systems.
\end{abstract}

\section{Introduction}

There has been some discussion in recent years which suggests that the way in which students learn has changed, and that sitting in passive mode in large lecture halls is not part of their expectation. In response to such perceptions, a group of academics at the University of Southampton embarked on a project to encourage active learning in large lectures and tutorials. The method chosen was to introduce the use of a personal response system or PRS for short (see for example http://www.educue.com/), sometimes also known as a classroom communication system. The system involves each student being equipped with a hand-held electronic transmitter, similar to a television remote control, called a PRS handset. These are known more colloquially to students as zappers and this is how we shall refer to them in this article. The zappers are used in conjunction with magic eyes or receivers placed at the front of the lecture theatre which are connected to software running on a personal computer. During the course of each session, the lecturer or tutor poses questions which students consider and answer via the transmitters, thereby providing activity for the students and feedback for the teacher. Although the introduction of activities into lectures and tutorials is not an innovation in its own right, the systematic collection of feedback and the additional analysis which is made possible by this technology-based approach, is a worthwhile addition. Furthermore, routine provision of such equipment in lecture theatres may serve as a stimulus for change in the standard methods of lecture delivery.

Classroom communication systems or PRSs have already been successfully introduced in the teaching of mathematics, engineering and science in both the USA and 
the UK. In particular, academics in Engineering at the University of Strathclyde have used a PRS in lecture theatres (the NATALIE project, see http://www.ltsneng.ac.uk/) to introduce a question-based approach to teaching (Boyle and Nichol, 2003). Lecturers use the response systems to increase the interactivity of lecture courses and, at the same time, enhance the feedback on the progress of understanding and learning during lectures for students and academics alike. The approach is used as a means of facilitating peer instruction in a large lecture context. It was not pioneered at Strathclyde but builds on a substantial experience and body of knowledge developed in the USA by several innovative groups - in particular the University of Massachusetts, Amherst, Physics Education Research Group (see http://umperg.physics.umass. edu/gemsFolder/umperg2/umperg_2000_09.pdf and Hake 1998) and Eric Mazur's group at Harvard (see http://mazur-www.harvard. edu/ and Mazur 1997).

The Southampton approach was the first to use the interactive sessions as a means of breaking up the conventional lecture period in a bid to monitor students' understanding. In particular, in the academic year 2002/3 it was used in a large class of 200 Aeronautics, Aerospace, Ship Science and Mechanical Engineering students in the first semester and a class of 120 Aeronautics and Aerospace Engineering students in the second semester. The basic approach was to combine conventional "chalk and talk' lectures with skeletal notes in order to set time aside for interactive sessions with the students. There are two modules involved, one in each semester, where each module consists of two lectures a week for 12 weeks. The assessment for each module consists of a final examination and a set of three or four extended pieces of coursework which consist of a series of examination-type problems. The students are offered tutorial support by their own engineering departments on a fortnightly basis; these are run by a mixture of lecturers, research assistants and postgraduate students. In the first use of the PRS technology, the intention was to replace a verbal method of interaction with the students with one utilising the zappers, but still keeping delivery of the syllabus sacrosanct.

However, once we were provided with the feedback from lectures, the importance of concentrating on essential key concepts became apparent. This then formed the basis for adopting a different approach to running some tutorials in Computer Science. Here, the approach was to ensure that the key concepts became thoroughly embedded. This may be particularly important for threshold students. Since this approach means that extra time needs to be spent on key concepts, students may be advised to study advanced material from additional notes, web-based resources or text books, and in their own time. This approach offers advantages to both the least and most industrious students. The former have more time dedicated to key concepts and the most industrious have an excellent base upon which to develop the deeper learning which they desire: both moving at their own pace and style. We discuss the two modes of exploiting the technology in the next two sections and then return to some general issues.

\section{Use in a large lecture class}

Here the basic idea was to exploit zappers to facilitate student interaction in large lecture classes (d'Inverno, 2003). The approach is somewhat different from other existing schemes using zappers in the UK and USA in that the aim remains one of 
delivering the whole rather than part of the syllabus. The problem with the approach of other groups is that their use of zappers is very time-intensive with the net result that they are able to deliver only part of the syllabus through lectures, an amount which varies between 30 and $70 \%$. The students are then required to study the rest of the syllabus independently. Although there may be much to recommend these approaches educationally, the non-delivery of the whole of the syllabus is probably unacceptable in many quarters. This would appear to be the case, for example, in mathematics service teaching, where the syllabus, once agreed upon, tends to become sacrosanct. The way in which the delivery of the full syllabus is achieved relies on using skeletal notes to free up time in lectures. This time can then be devoted to using the zappers to accommodate greater student interaction. We first give some brief background on skeletal notes, motivate the need for greater student interaction and describe briefly the current use of zappers.

Skeletal notes consist essentially of full printed lecture notes in which the right hand sides of the equations are missing (d'Inverno, 1995). The missing parts are then added in the lectures. In this way it proved possible to provide students with a full set of lecture notes, which include a lot of textual material to help make the notes readable, and yet the students write in the bulk of the mathematics themselves in the lectures. More importantly, by eliminating the redundant process of copying down text inherent in conventional lectures, it released some time in the lectures for more interactive forms of teaching. It is worth remarking that the skeletal notes approach proved to be very popular with students. This popularity led to colleagues in several other faculties and institutions adopting the approach, although with a number of variations.

We next ask the question: Why is there a need to increase student interaction in large lectures? First of all, anything that breaks up a lecture is valuable because it gives students the chance to take a breather and to refocus. It is well known that most people cannot concentrate for extended periods beyond about 20 minutes. A break in the lectures of any kind is therefore often helpful. Secondly, student interaction means that, in some limited sense, the students are being treated more like humans. The monolithic lecture based on relentlessly copying down notes could well take place without the students being present (apart from any copying actually taking place!). Thirdly, it means that one has the opportunity to put in more light and shade: by looking at structural issues, reinforcing important points and so on. Finally, it provides one with some means of monitoring the students' understanding and checking that the lectures are proceeding at an acceptable pace. If we are to expect students to attend lectures then there surely needs to be some 'value added', other than that of providing them with a complete set of notes, and student interaction can provide some of this value-added component. Although there is quite a lot of literature about developing student interaction in lectures and large groups in the Arts and Humanities, these approaches do not work so well in more technological subjects, and this was why the idea arose of using zappers.

The actual use of zappers has been rather naïve to date and has mostly consisted of asking the students to answer multiple-choice questions without conferring. Nonetheless, it appeared to be the case that a large cohort of students, typically around $40 \%$, get the answers to simple questions wrong. It could be that the students in this particular group are deliberately giving the wrong answer because they disapprove of 
the technology. End-of-unit questionnaire results revealed that the use of the system polarised the class into those in favour of its use ('an exciting new development') and those against ('stop messing around with technology and get back to good basic teaching'). It may simply be disengagement that lies behind the observation. After all, most of the lectures which students attend require little engagement and they may well have developed a passive mentality in which a significant cohort largely expect to switch off in lectures. The general findings of the survey of student opinion are that the students find the system easy to use (especially when the student's response had a fixed position on the display grid) and the system worked some $95 \%$ of the time. The questions asked were not always as clear as they could have been, and sometimes involved typos. It appeared to the students that the lectures were sometimes rushed in order to fit in the zapper session. Moreover, the session was always held at the end of the lecture and some students felt it could be used more beneficially at other points in the lecture. A cohort of students still see the system as a waste of time, but the majority of students appear to welcome its use. The final question 'Would you recommend that zappers were used in other lectures' produced a $75 \%$ response in favour, which suggests that we should continue to develop the use of the system.

An important consideration is to find out more about different types of modalities of questioning that can be employed. Applications across a number of UK institutions have followed on from the initial example provided by Mechanical Engineering in Stratchclyde University. Academics have implemented personal response style systems across a range of different disciplines, teaching contexts and questioning approaches (McCabe et al., 2001; Draper and Brown, 2002; Elliott, 2003; Madill, 2003). In particular, it would be useful to build up a data bank of questions that illustrate these modalities. One issue that needs addressing here is whether there are questioning paradigms that allow students to discuss answers with each other before voting, rather than voting without conferring, which is supposed to happen at present. The other issue is to try and track more precisely what goes on in these sessions. In particular, is the 'wrong-answer-cohort' a real feature of this type of activity and, if so, why is this?

\section{Use in a large tutorial}

Shortly after the introduction of the zappers into the teaching of Engineering Mathematics, they were employed in a first year Computer Science unit for students studying their first programming course. This experience to some extent mirrors and highlights some of the outcomes articulated above.

In this case, the zappers were employed in a tutorial, which was delivered by a different member of staff from the lecturer teaching the main class. The tutorial was voluntary and intended for those who needed extra help with the material that had been covered in the preceding week. The decision had been taken to identify the simple most important topic in the week's work, and tackle only this, but approach it from a completely different angle. The teaching methods employed were group oriented and participatory. A small problem was explained at the start of the tutorial and the intention was that small groups of students would work together to solve the problem in parts, responding to questions using the zappers at intermediate stages. In the event, the tutorials never went according to plan. At an early stage the zapper 
responses to the questions would reveal very deep and important gaps in understanding, given which, the tutorial could not continue as planned; instead it proved necessary to reinvent the tutorial pretty much on-the-fly in order to respond to the most important needs of the students.

The student response to the quality of these tutorials was excellent (mode average 5, mean 4.4 , on a scale 1-5). The lectures were attended by an average of 40 students from a total cohort of 160 (in fact the number attending actually increased as the semester progressed) and this number corresponded pretty accurately to our estimate of the number of students that would require extra help with this module. This tutorial was unusual in that it was not motivated by the need to cover any particular content (which was already covered by other lectures and by a parallel lab course) but rather by the desire to provide the most useful and timely reinforcement for the students. As it turned out, the help that the students wanted was always at a much more fundamental level than had previously been assumed.

\section{Conclusions}

A key aim of the original project was to introduce and evaluate active learning methods into lecture theatre teaching through the use of PRSs to support a questionbased approach. Academics in the UK are frequently criticised in quality reviews for failing to provide students with sufficient or timely feedback (Marburger, 2001). The use of a PRS system can ensure that there is that feedback. However, the feedback is not only directed at the learners, but it can also significantly benefit the teacher in terms of acquiring some insight into the possible impact of the teaching approaches they are using.

An unanticipated outcome of introducing the technology in both the lectures and the tutorials was an increased understanding of the precise places where students were failing to understand. The lecturers' increased understanding was a direct result of the impact of the, albeit limited, dialogue that such approaches initiate between learner and teacher. As a result of learning this information, teachers, given the opportunity, tend to concentrate on such issues, possibly leaving those students that can cope with the advanced work to do so in their own time.

In this way the introduction of the PRS has proved to be a powerful tool in providing a focus for academics in Engineering and Mathematics to explore and experience new approaches within the lecture and tutorial formats. It may even be viewed as providing a reflective tool for academics through which they can engage in their own educational and staff development. Its strength may lie in the fact that academics are able to introduce innovations and gain feedback in a context which is well aligned to the natural approach of their subject discipline (Neumann et al., 2002). In our limited experience the use of the systems has motivated changes in teaching approach, and this has clearly been borne out by experiences at other institutions in the UK, e.g. Strathclyde and Glasgow.

The understanding derived so far from the project is that the experience suggests it would be appropriate for use in different subject areas within the general science and technology focus. From the students' point of view it would seem that, for many, using zappers has effectively enhanced the learning environment, supported or motivated the development of more flexibility in teaching approaches and helped 
make teacher-led learning environments more student centred. Our test of these conclusions will be to see whether we can communicate and extend this practice to a wider range of our academic colleagues.

\section{References}

Boyle, J. T. \& Nichol, D. J. (2003) Using classroom communication systems to increase interaction and discussion in large class settings. Studies in Higher Education, 28, 457-473.

D’Inverno, R. A. (2003) Making Lectures Interactive. MSOR Connections, 3, 18-19.

D'Inverno, R. A. (1995) On the use of skeletal notes. International Journal of Mathematics Education, Science and Technology, 26, 195-204.

Draper, S. W. \& Brown, M. I. (2002) Use of the PRS (Personal Response System) handsets at Glasgow University, Interim Evaluation Report, March 2002 (http://www.psy.gla.ac.uk/ steve/ilig/interim.html).

Elliot, C. (2003) Using a Personal Response System in Economics Teaching. International Review of Economics Education, 1, 1 (http://www.economics.ltsn.ac.uk/iree/i1/ elliott.htm).

Madill, W. (2003) Improving student interaction via a personal response system and peer instruction, Best Practice Building Network Case Study Teaching Learning and Assessment (www.be.coventry.ac.uk/BPBNetwork/ casestudy/uce_tla3i.htm).

Hake, R. R. (1998) Interactive engagement versus traditional methods: a six thousand survey of mechanics test data for introductory physics course. American Journal of Physics, 66, 64 74.

McCabe, E. M., Heal, A. \& White, A. (2001) The Integration of Group Response Systems into Teaching and LOLA, the Missing Link in Computer Assisted Assessment, $5^{\text {th }}$ International Conference on CAA. (http://www.lboro.ac.uk/service/ltd/flicaa/conf2001/ $\mathrm{pdfs} / \mathrm{d} 2 . \mathrm{pdf})$.

Marburger, D. R. (2001) Absenteeism and Undergraduate Exam Performance. The Journal of Economic Education, 32, 99-109.

Mazur, E. (1997) Peer Instruction: A User's Manual. Prentice Hall, NJ.

Neumann, R., Parry, S. \& Becher, T. (2002) Teaching and Learning in Their Disciplinary Contexts: a Conceptual Analysis. Studies in Higher Education, 27, 405-417.

Ray d'Inverno is Associate Dean (Education) for the Faculty of Engineering, Science and Mathematics at the University of Southampton. He was appointed as a Mathematics Lecturer in the Department of Mathematics, University of Southampton, in 1970. He was subsequently promoted to Senior Lecturer and Reader and finally to a Chair in General Relativity in 1995. He has taught both applied mathematics and pure mathematics as well as computer science and he also taught for 3 years in the Music Department at the University of Southampton where he first introduced Jazz into the curriculum. He has taught service courses in both the Engineering and Science Faculties. In particular, in 1974 together with Dr Leslie Cohen, he introduced the well-known Self-paced Mathematics Course for First Year Engineers which still runs today, albeit in a modified form, and it has become one of the largest innovations in the UK. He has also taught mathematics to second year engineers for over 30 years. He is currently Deputy Dean for Learning and Teaching in the Mathematics Faculty. His research interests include Computer Algebra in General Relativity and Numerical Relativity. 
Hugh Davis is head of the Learning Technologies Group and a senior lecturer in the School of Electronics and Computer Science at the University of Southampton where he has been based since 1987. As an undergraduate at the University of Southampton he experienced the teaching of mathematics to engineers first hand. As director of Learning and Teaching in Engineering he has been responsible for leading a range of innovations in teaching approaches at the University. He has over 100 published papers in the area of hypertext system design and applications in educational contexts, he holds a number of grants in projects exploring the uses of technology in learning.

Su White is a Learning and Teaching Co-ordinator in the Faculty of Engineering, Science and Mathematics at the University of Southampton and a member of the Learning Technologies Group in the School of Electronics and Computer Science. She is project leader for the UK Electrical and Electronic Engineering Assessment Network ( $e^{3}$ an). Her research interests include a strong focus on the organisational change brought about by the use of learning technologies in Higher Education. Su was previously manager of the University's Interactive Learning Centre and Southampton co-ordinator for a national Teaching and Learning Technology Support Network Centre.

Address for correspondence: Faculty of Engineering, Science and Mathematics, University of Southampton, Southampton SO17 1BJ, UK. E-mail: saw@ecs.soton.ac.uk 